\title{
Polygonal faults in chalk: insights from extensive exposures of the Khoman Formation, Western Desert, Egypt
}

Barbara J. Tewksbury, John P. Hogan, Simon A. Kattenhorn, Charlotte J. Mehrtens, and Elhamy A. Tarabees

\section{Index to supplementary material}

Isotopic analysis - methods and results.

Figure DR1: Fig. 2a (full resolution); additional field photo of calcite vein fins along faults ..... 3

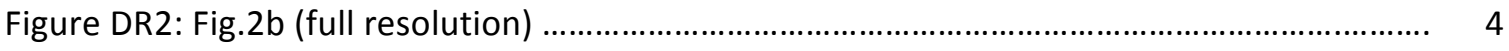

Figure DR3: Fig. 2c (full resolution); additional field photo of fault surface grooves................... 5

Figure DR4: Fig. 2e (full resolution); additional field photo of euhedral calcite in vein ............... 6

Figure DR5: Field photos of multi-phase calcite vein and veins with T intersections.................... 7

Figure DR6: Fault map and histogram................................................................................ 8

Figure DR7: Fig. 2h (full resolution); additional field photo of faults of multiple orientations.... 10

Figure DR8: Fig. 3a (full resolution); additional satellite images of basin-capped mesas............ 11

Figure DR9: Fig. 3b (full resolution); additional field photo of rays........................................... 13

Figure DR10: Field photos of iron oxide/iron sulfide mineralization ........................................... 14

Figure DR11: Satellite images of context for schematic diagram; Fig. 3c (full resolution)........... 16 


\section{Isotopic analysis of samples from the Khoman Formation}

Samples: We obtained a small amount of carbon and oxygen isotope data from the Khoman host rock and from samples along transects across two calcite-filled veins within polygonal faults $(n=14)$.

Methods: Between 10 and 19 grams of carbonate were obtained from each sample by rotary drill, and $\mathrm{CO}_{2}$ gas was extracted by reaction with phosphoric acid. All analyses were performed on a dual inlet V.G. SIRA II stable isotope ratio mass spectrometer at the University of Vermont Environmental Stable Isotope Laboratory.

Results: $d^{13} \mathrm{C}$ values ranged between 0.15 and $-4.50 \%$ (mean $=-0.3 \%$; $S D \pm 0.32$ ) and $d^{18} \mathrm{O}$ varied from -3.74 to $-14.45 \%$ (mean $=-7.6 \%$; $S D \pm 1.04$ ). Results are reported in per mil (\%o) units relative to $\mathrm{V}$-PDB and precision of measurements is $\pm 0.05 \%$ for both $\mathrm{C}$ and $\mathrm{O}$.

Interpretation: Although sparse in number, the data from both vein and host rock samples are consistent with preserving a record of multiple fluid components, one intrinsic to the marine sediments and the other being isotopically light meteoric waters. There is no isotopic evidence in these samples that elevated temperatures and evolved brines characteristic of deep burial were associated with calcite vein formation in the Khoman Formation. We interpret the isotopic signature to represent either a meteoric role in the fluids that precipitated the calcite veins or, more likely, re-equilibration of formation-derived fluids after vein emplacement. Oxidation of iron sulfides in the Khoman to oxides and hydrous iron oxides is consistent with this interpretation. 

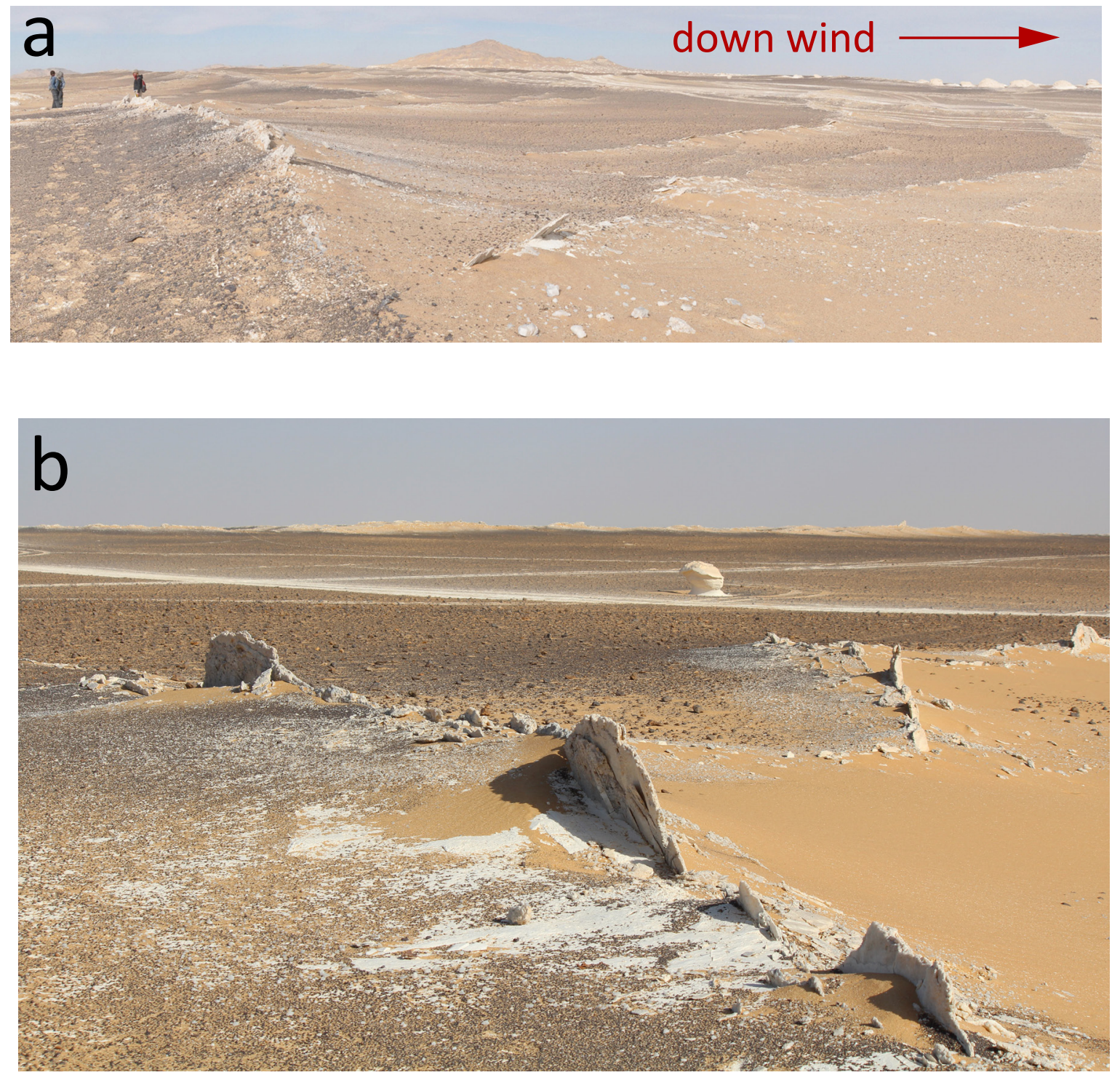

Figure DR1: (a) Full resolution of Figure 2a. (b) Additional field photo of intersecting calcite veins (fins) of diverse orientations.

Calcite veins mark the locations of normal faults that exhibit both linear and curved fault traces and that intersect at angles ranging up to $90^{\circ}$. Fault dips are steep (typically 70 to nearly $90^{\circ}$ ). Topographic relief is negligible.

In DR1b, the host chalk is visible in the foreground as low white patches. Although the White Desert of the Farafra area is famous for erosional remnants of white chalk such as the one in the middle distance, much of the chalk is mantled by surficial deposits. Dark surface lag derived from iron oxide (originally iron sulfide) mineralization in the chalk occurs on the upwind sides of the low calcite veins, with light colored aeolian sand down wind.

Locations: a) $27.16322 \mathrm{~N}, 28.02839 \mathrm{E}$. b) $27.18415 \mathrm{~N}, 28.02466 \mathrm{E}$. 


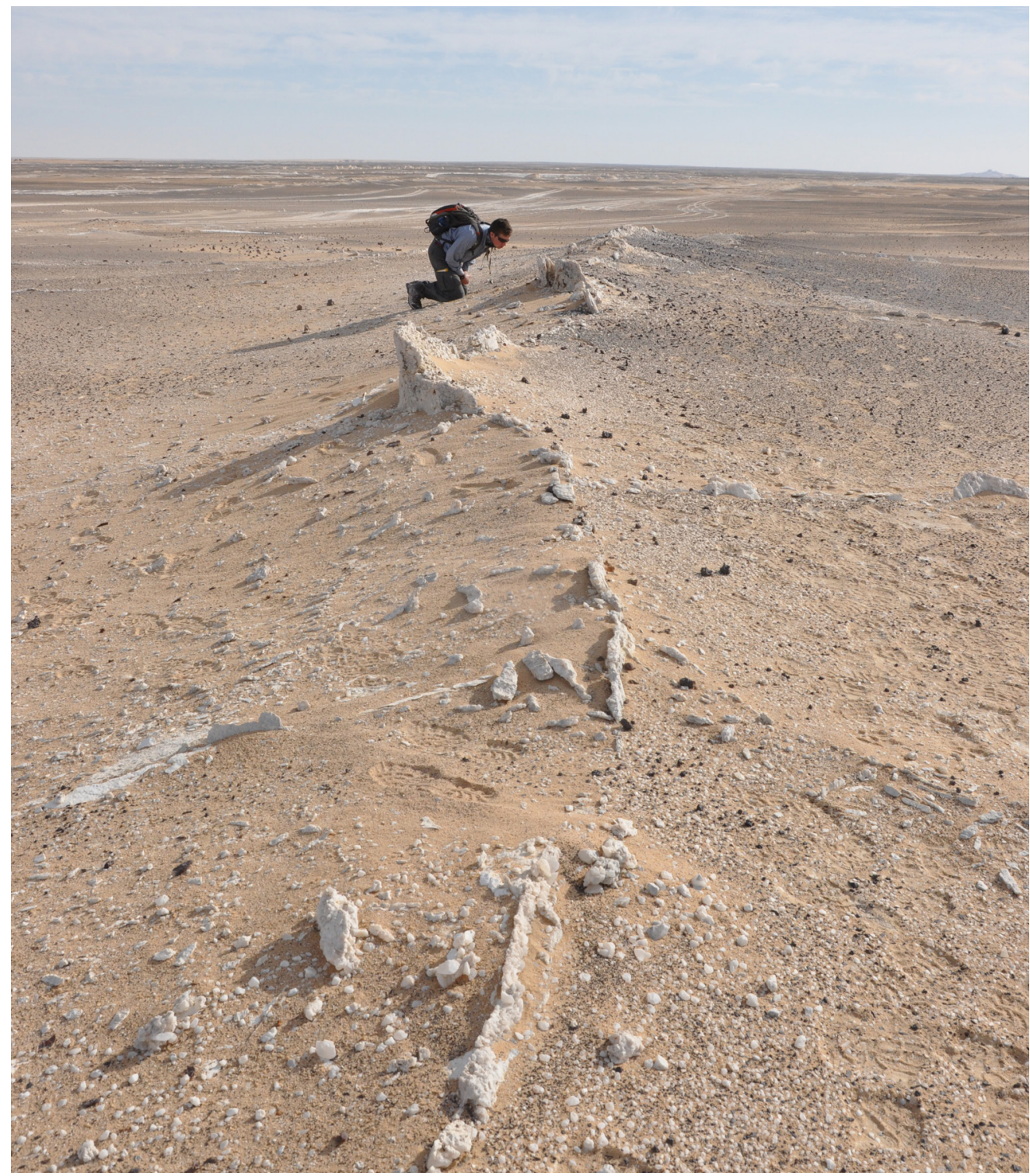

Figure DR2: Full resolution of Figure $2 \mathrm{~b}$. View along-strike of a calcite vein along a sinuous, steeply dipping polygonal fault. Cuspate fault traces, such as the one in the middle distance, are common. Additional faults marked by calcite veins (foreground and middle ground right) intersect this fault at high angles. Location: $27.16322 \mathrm{~N}, 28.02839 \mathrm{E}$. 

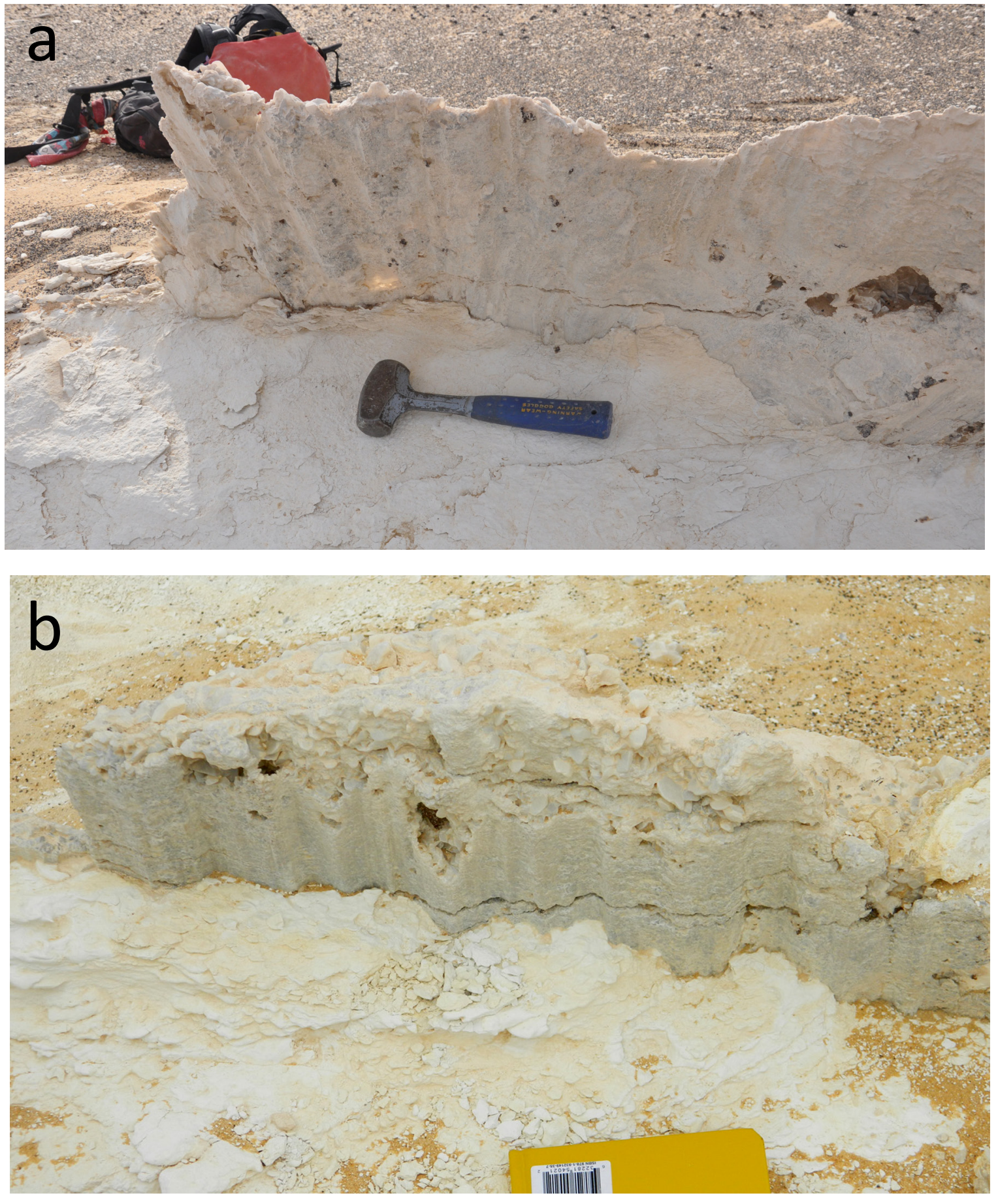

Figure DR3: (a) Full resolution of Figure 2c. (b) Additional field photo of calcite vein along steeply dipping fault in host rock massive white chalk. Faults in the Khoman are characterized by steeply plunging grooves along fault surfaces, with coarse calcite crystallized in veins that preserve casts of the fault grooves. The host chalk adjacent to the fault shows a narrow zone of brittle damage. Rock hammer in (a) is $27 \mathrm{~cm}$ long; yellow notebook in (b) is $9 \mathrm{~cm}$ across. Locations: a) $27.16360 \mathrm{~N}, 28.02759 \mathrm{E}$. b) 27.156150N,28.02345E. 

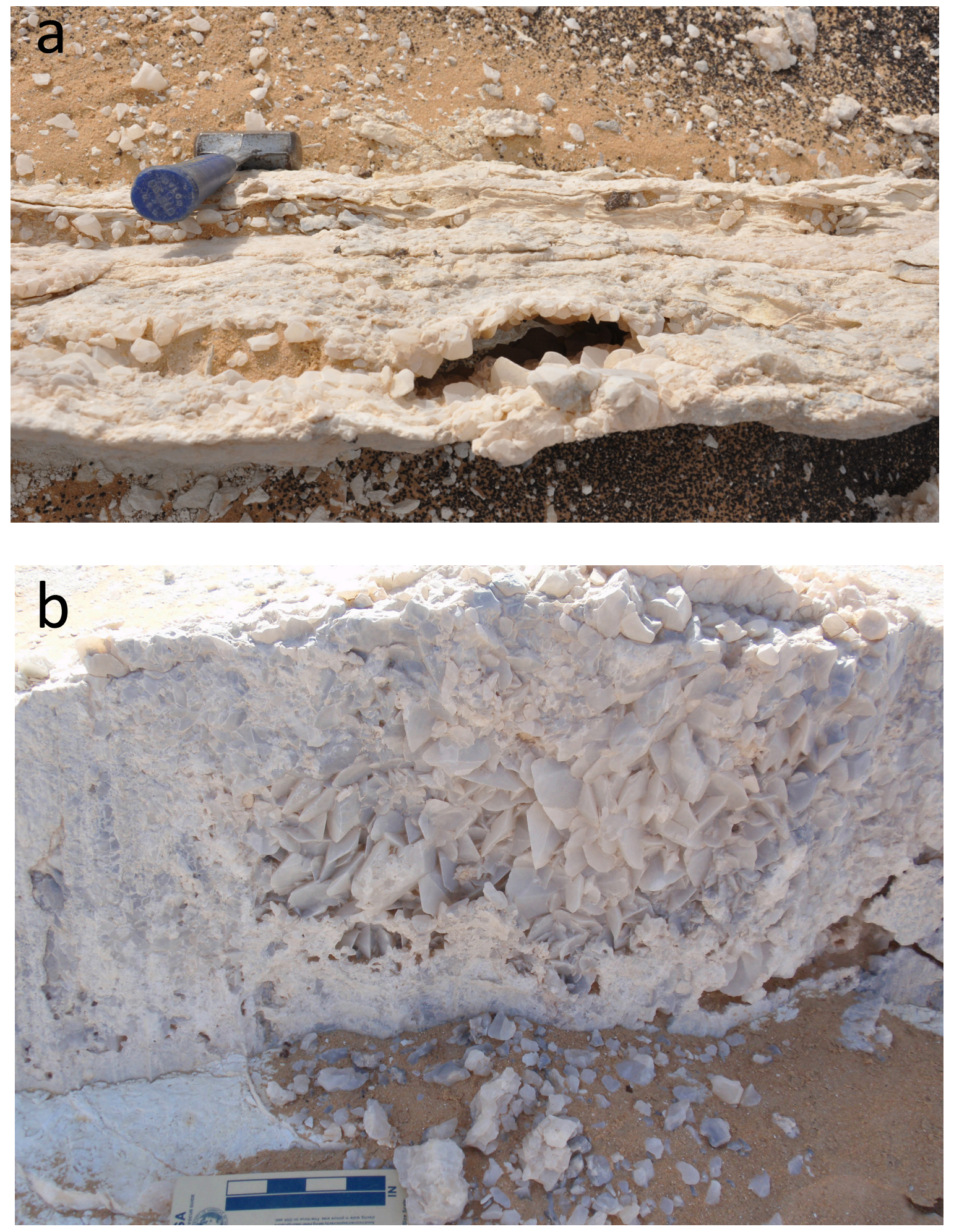

Figure DR4: (a) Full resolution of Figure 2e. (b) Additional field photo of calcite crystals within a vein. Veins range in thickness up to $25 \mathrm{~cm}$ and consist of coarse calcite crystals that extend perpendicular to fault surfaces. Euhedral crystals suggest growth of calcite into dilational space within a vein along a fault. Rock hammer head in (a) is $9 \mathrm{~cm}$ long. Locations: a) $27.16360 \mathrm{~N}, 28.02759 \mathrm{E}$. b) $27.16136 \mathrm{~N}, 28.02221 \mathrm{E}$. 

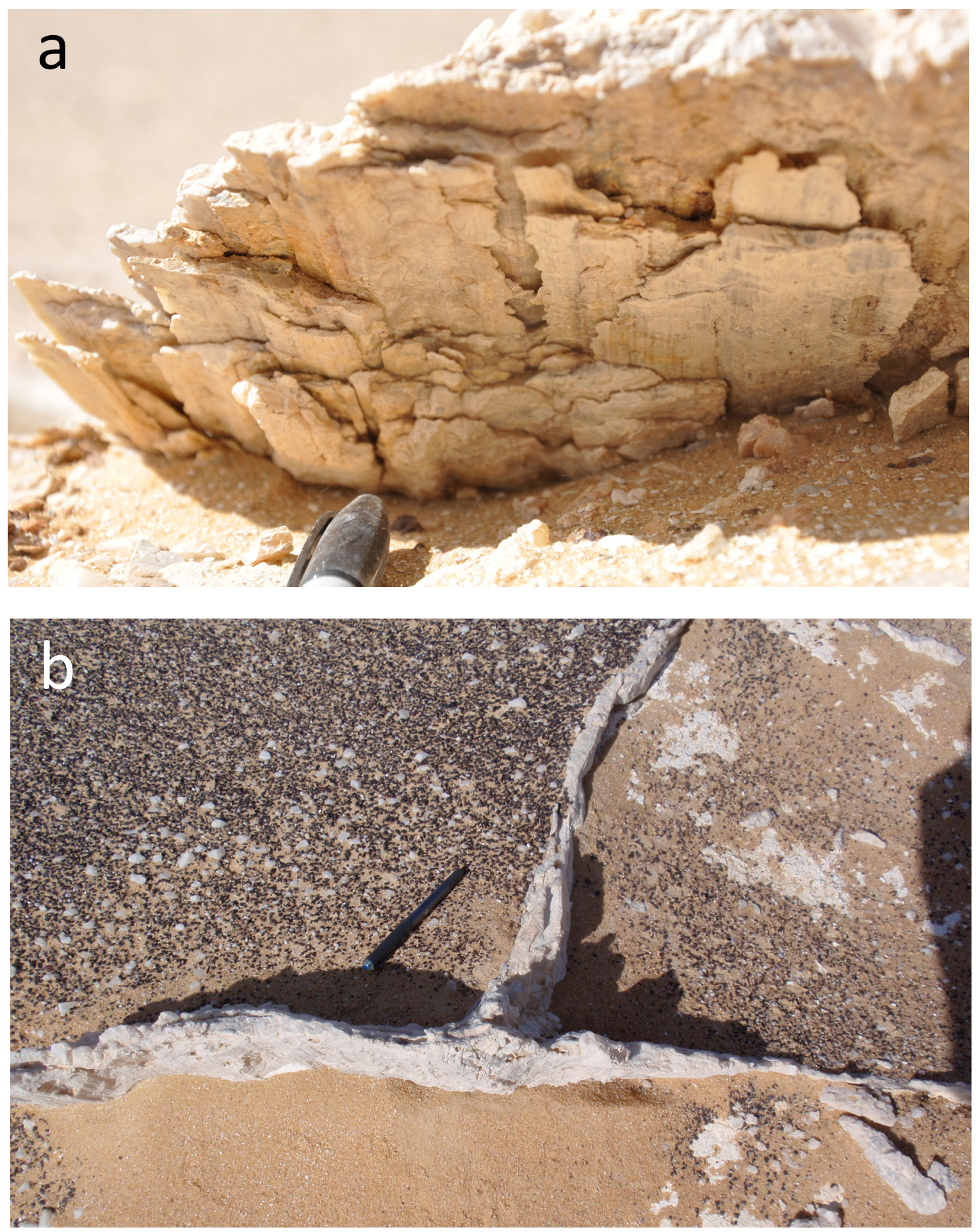

Figure DR5: (a) Calcite veins along faults typically display multiple phases that commonly preserve slivers of chalk between veins. Many have steeply plunging internal lineations suggesting repeated episodes of calcite precipitation along grooved surfaces. This may reflect overlap in the timing of faulting and vein formation episodes. Black pen cap is 1.5 $\mathrm{cm}$ wide. (b) Nearly vertical veins of coarse calcite intersect at a T-junction. Veins are not truncated within this junction, suggesting simultaneous dilation in orthogonal directions. Pen is $13 \mathrm{~cm}$ long. Locations: a) $27.29022 \mathrm{~N}, 27.94242 \mathrm{E}$; b) $27.16187 \mathrm{~N}, 28.02139 \mathrm{E}$. 


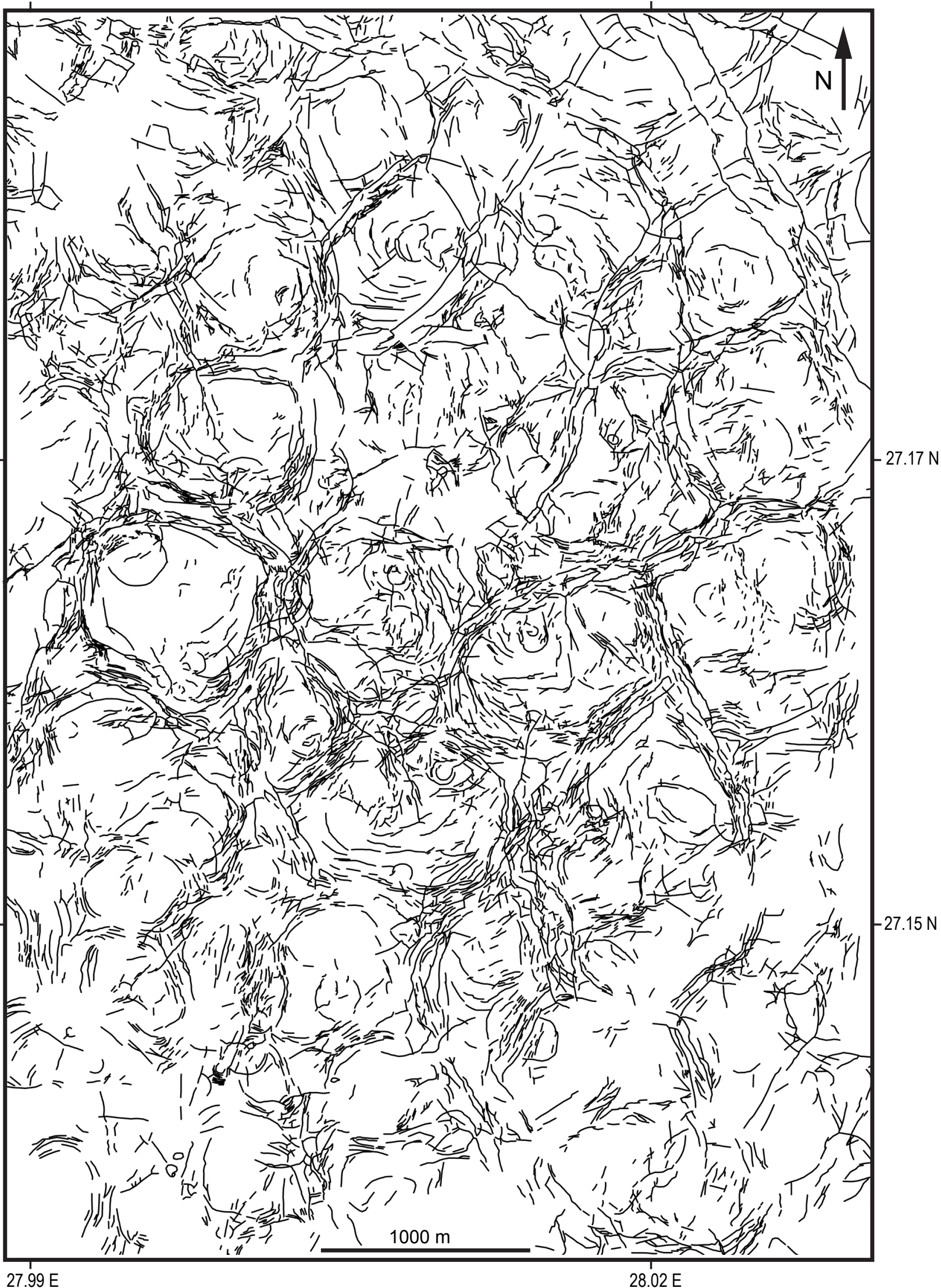

$27.99 \mathrm{E}$

28.02 E

Figure DR6a: Map of all faults mapped in a $25 \mathrm{~km}^{2}$ area using high resolution ( 1 $\mathrm{m} /$ pixel) satellite imagery. The northern half of this map area appears in Fig. 2g. We chose this area to map because it is representative of fault patterns in the Khoman and because surficial deposits do not mask the faults except in small portions of the area. 


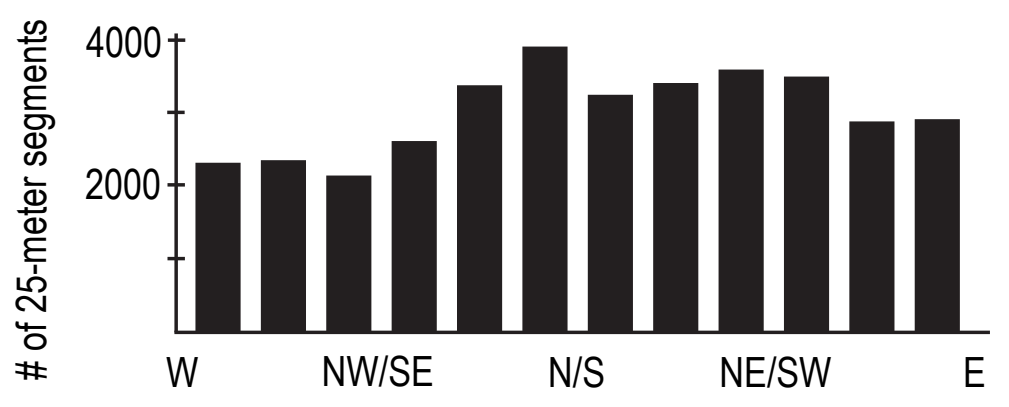

Figure DR6b: Histogram of polygonal fault orientations. In order to analyze fault azimuths in ArcMap, we first divided all of the faults mapped in Fig. DR6a into 25-meter segments in order to more accurately represent the orientations of the many curved faults in the Khoman. We used the Polyline Get Azimuth tool in EasyCalculate 10, an add-on for ArcGIS 10, to determine the azimuth of each 25 -meter segment. It is valid to correlate these azimuths with fault strike because 1) fault dips are very steep, and 2) there is essentially no topographic relief in the area. The histogram above shows fault azimuths grouped into $15^{\circ}$ bins and reveals no dominant or characeristic fault orientations. 

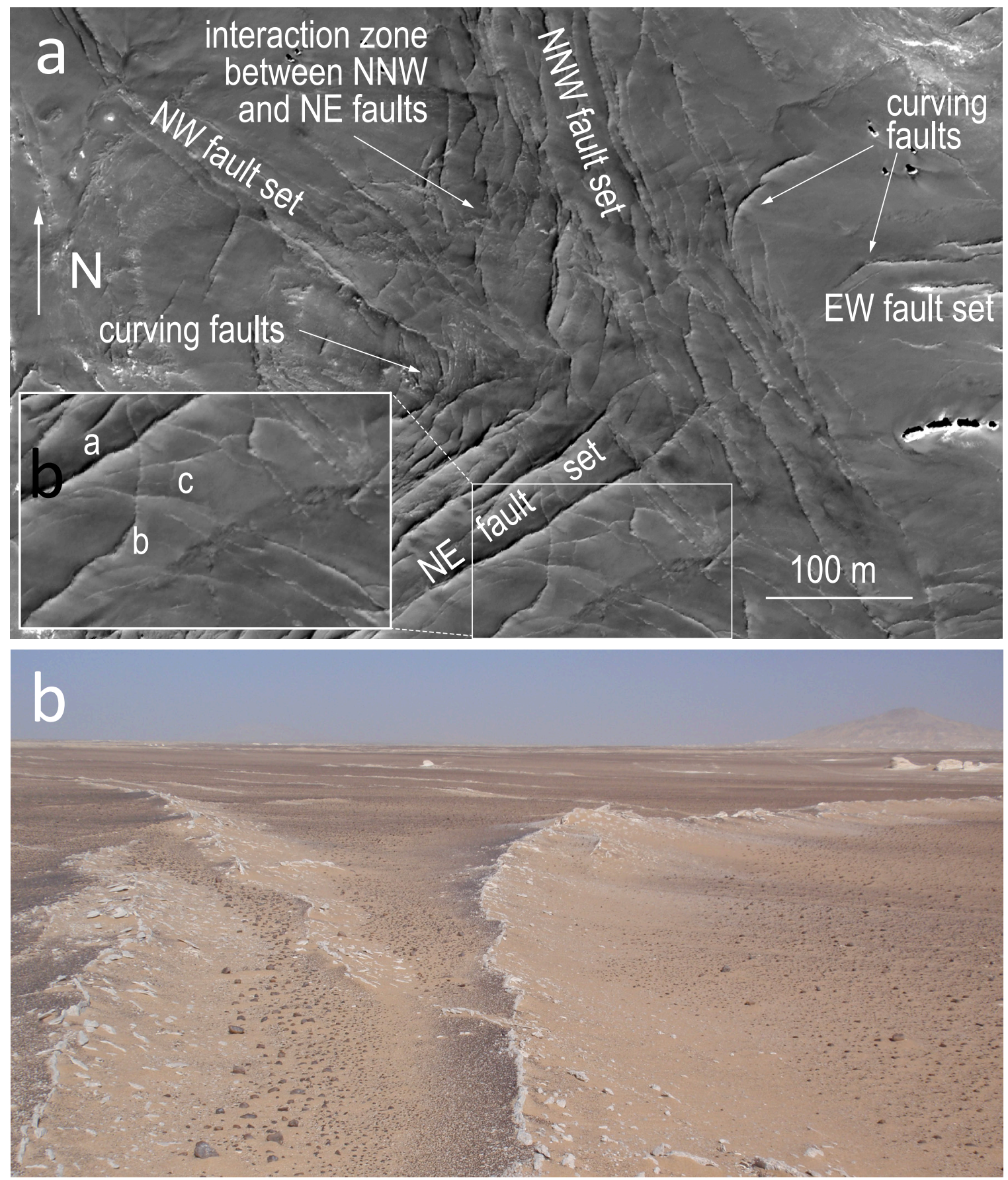

Figure DR7: (a) Full resolution of Figure 2i showing multiple orientations of clusters of veins along the arms of the polygonal fault system. Contemporaneous activity along faults with different orientations is shown by the development of complicated interaction zones between the polygon arms and faults that curve in orientation from one arm into an adjacent arm. Inset figure shows differently oriented faults $a, b$, and $c$ that have ambiguous crosscutting relationships, indicating overlap in the timing of fault development. (b) Calcite veins along polygonal faults with diverse orientations; photo taken within the interaction zone in DR7a. The lack of preferred fault orientations, gradual changes in strike of curved faults, as well as intersections between faults without clear crosscutting relationships, is consistent with fault propagation within a horizontally radially isotropic stress field. Location for b: $27.16187 \mathrm{~N}, 28.02139 \mathrm{E}$. 


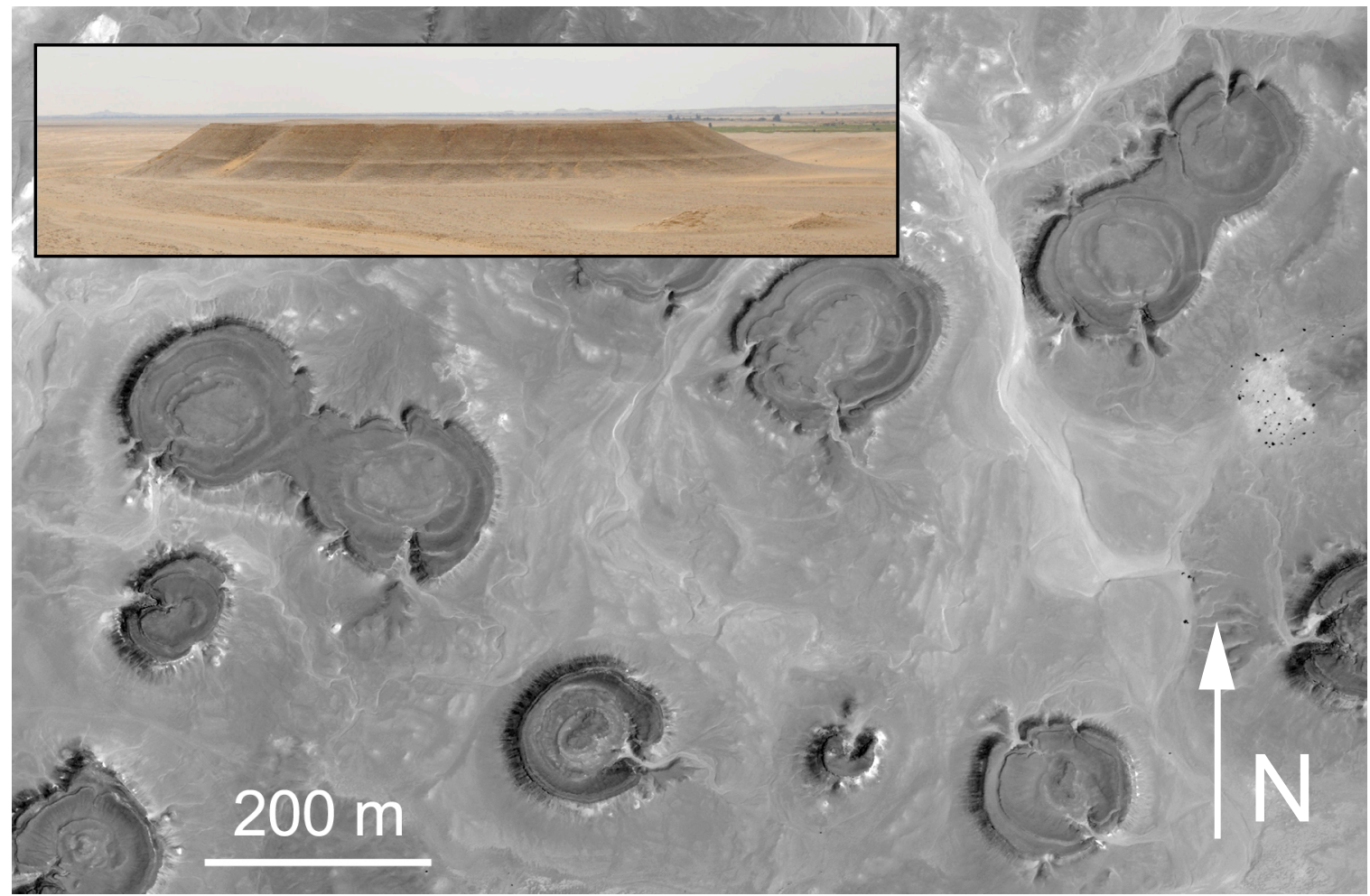

Figure DR8a: Full resolution of Fig. 3a. Low circular mesas 50-200 m across in the upper part of the Khoman Formation are capped by a thin layer of resistant limestone. Both field observations and satellite imagery show that the mesas have concave tops and that the capping layer dips shallowly inward toward the centers of the mesas. These small circular structural basins occur in layers that are otherwise essentially horizontal. Sun illumination direction is from the SE. Inset location: $27.23345 \mathrm{~N}$, 27.93142E.

Figure DR8b (next page): Google Earth images from the northwestern portion of the Farafra Valley show the distribution and characteristics of the small circular basins and their spatial relationship to the polygonal faults. All images have been contrast-enhanced in PhotoShop.

DR8b-1: In this location map, stratigraphically higher portions of the Khoman occur in the NW and stratigraphiclly lower portions in the SE. The main area of polygonal faults is SE and $E$ of this image. Image center: $27.243503 \mathrm{~N}, 27.963527 \mathrm{E}$.

DR8b-2: Small mesas with concave tops capped by an inward-dipping resistant limestone layer. Image center: $27.268487 \mathrm{~N}, 27.982783 \mathrm{E}$.

DR8b-3, 4, and 5: Some of the basin-capped mesas are cut by polygonal faults extending upward from the polygonal fault horizon below. Field observations show that the faults are steeply dipping, normal slip faults with the same kind of grooved veins of coarse calcite that occur in the main polygonal fault terrain. The red star in Figs. DR8b-3 and DR8b-5 shows the location of the fault in field photo DR8b-4, with the look direction for the field photo shown with a red arrow in DR8b-5. The yellow star shows the same basin-capped mesa in the satellite image and the field photo. Image centers: DR8b-3 27.239445N, 27.943102E; DR8b-5 27.241524N, 27.944473E. DR8b-4 looks SW from 27.240895N, 27.943288E.

DR8b-6: This area lies stratigraphically between the terrain of basin-capped mesas above and the main horizon of polygonal faults below. The zone is characterized by low-relief small circular basins that are spatially associated with polygon-bounding fault clusters and intersections and cut by polygonal faults. Some of the small circular basins have prominent radial rays. The outline shows the area of Figure DR9a. Image center: 27.225454N, 27.978842E. 

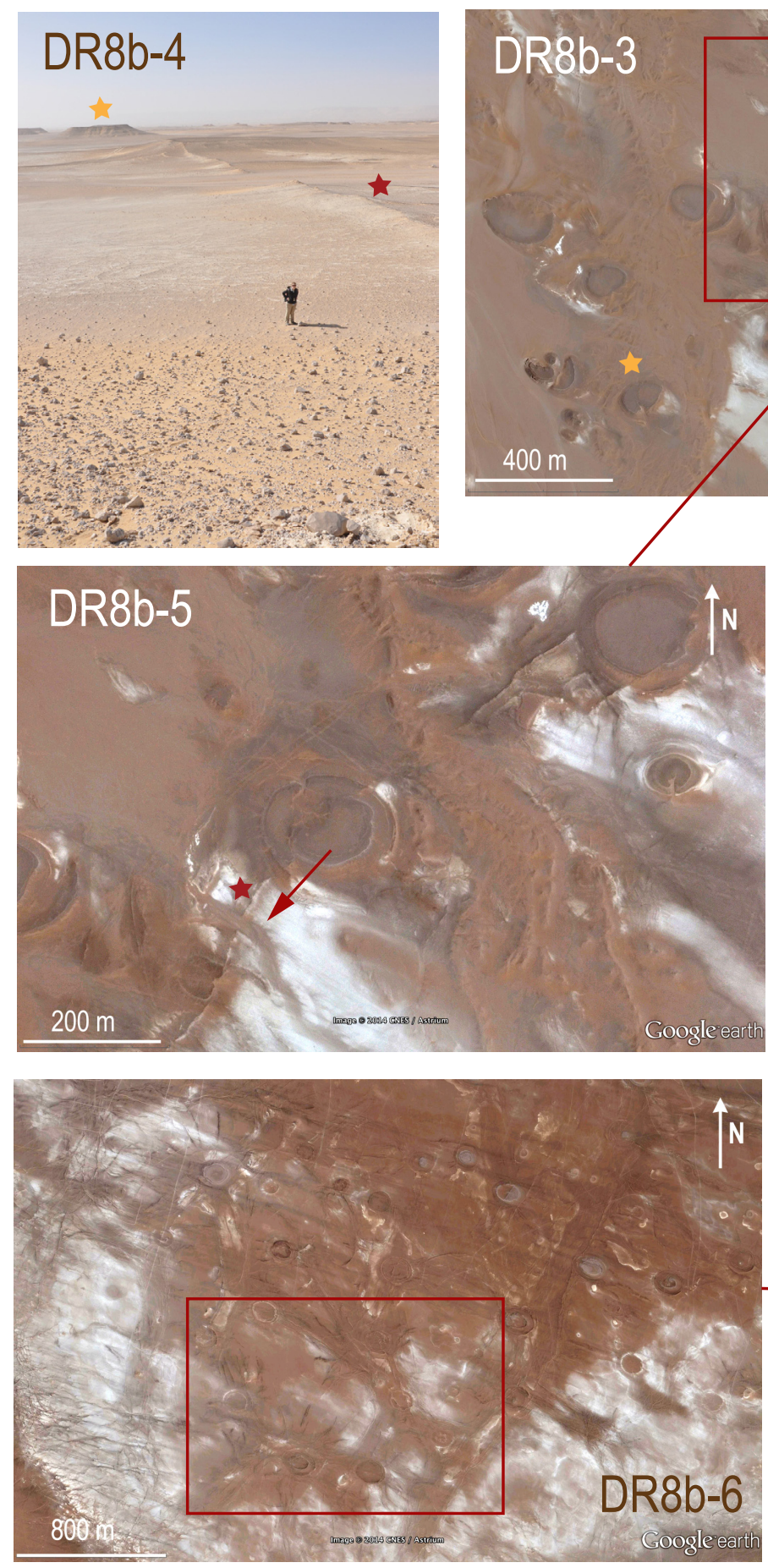
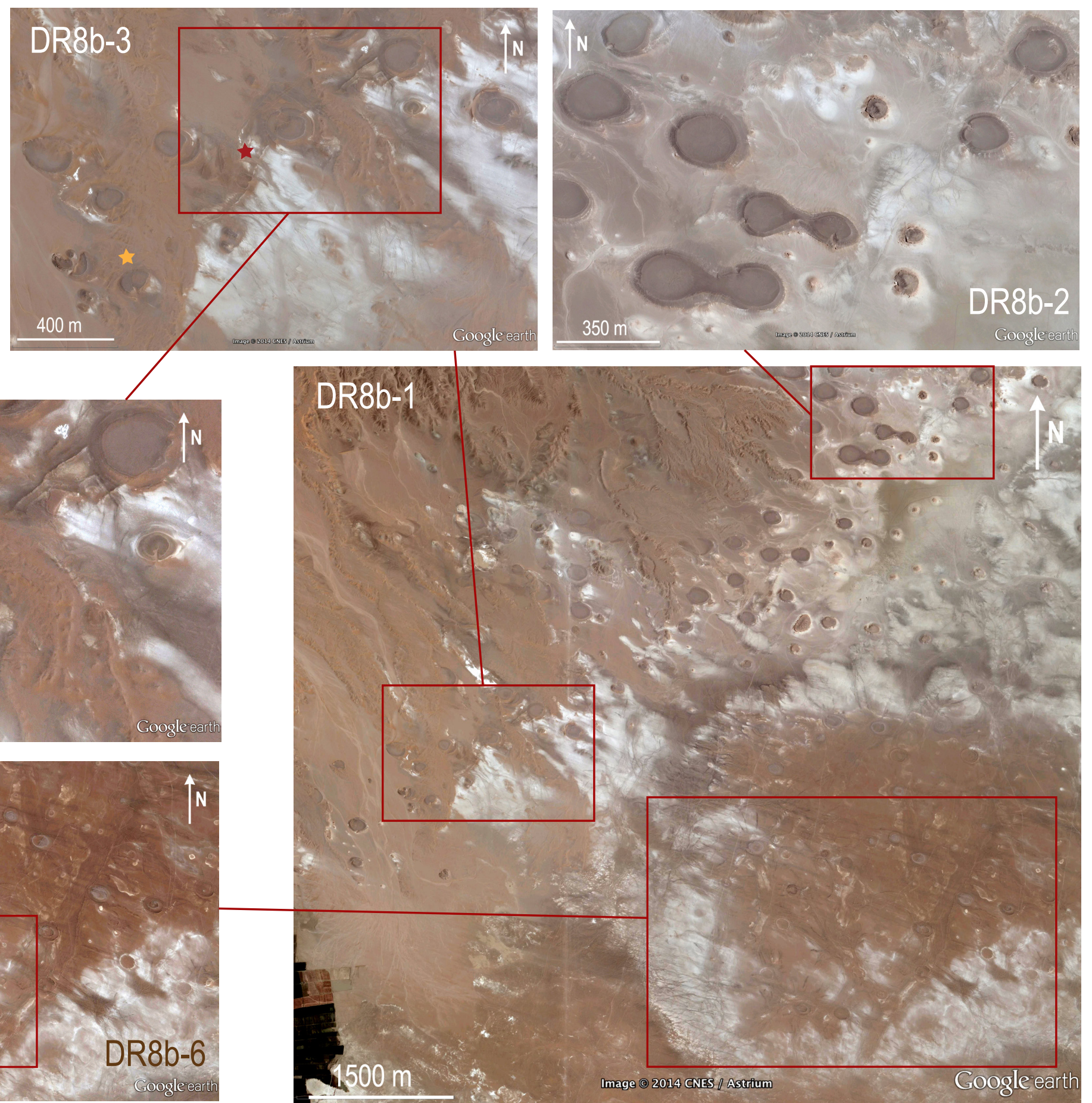

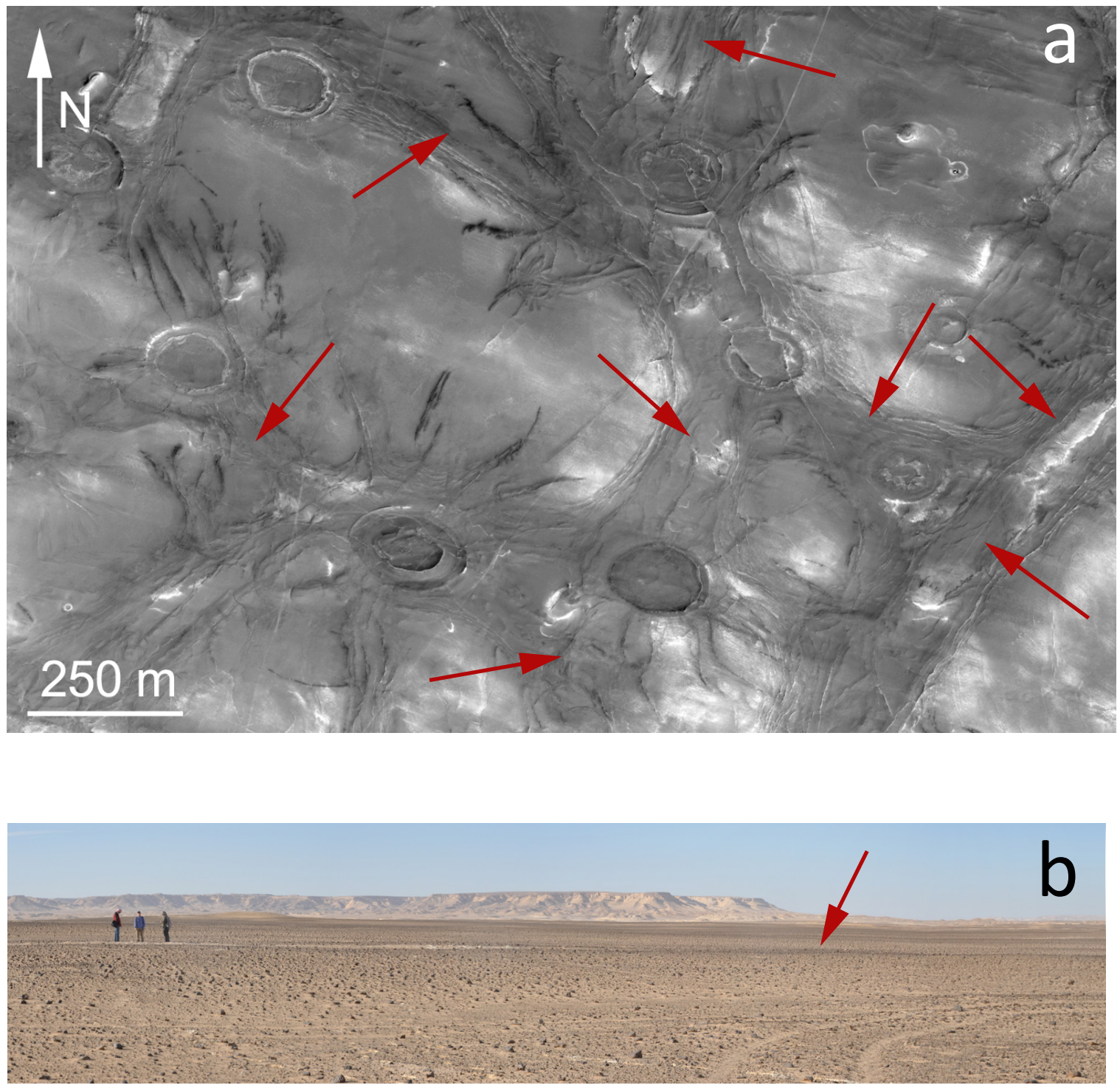

Figure DR9a: Full resolution of Fig. 3b, location shown in Figure DR8b-6. Small low-relief basins occurring in strong spatial association with polygon boundaries and triple junctions (shown with red arrows) are cut by polygonal faults. Some basins display radial vertical veins of calcite and goethite (originally pyrite or marcasite) that appear dark in the panchromatic satellite image.

Figure DR9b: The dark rays that are so prominent in the satellite imagery are difficult to see in the field and show up as subtle, slightly darker streaks in the desert pavement (red arrow). The darker color is caused by scattered dark-colored fragments weathered from narrow goethite veins (see Figure DR10a for a view of the vertical goethite veins).

Location: 27.21949N, 27.97431E. 

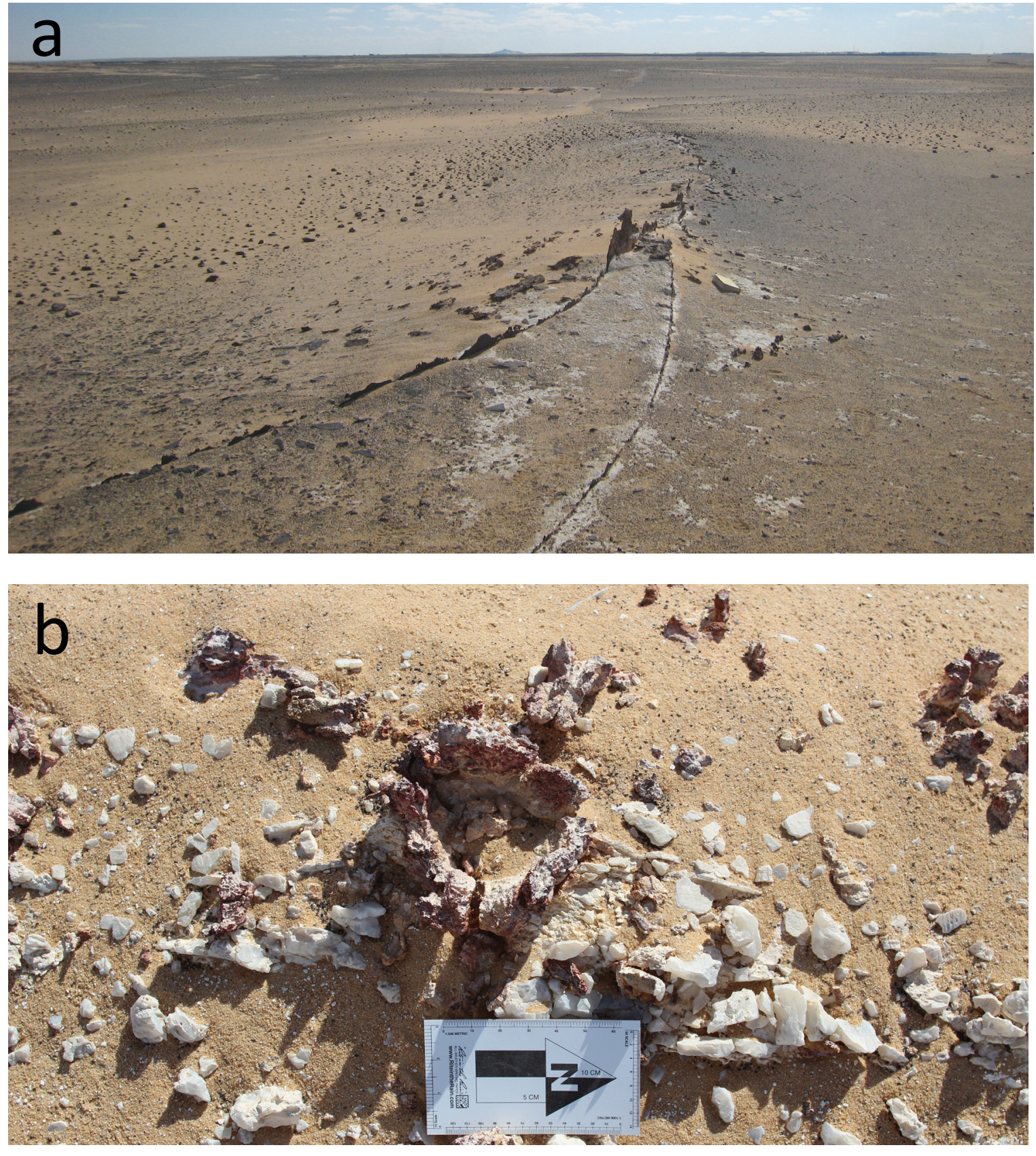

Figure DR10: (a) Narrow vertical veins of goethite (originally pyrite or marcasite) in the chalk. Veins are narrow (a few $\mathrm{mm}$ ), with linear or broadly curved outcrop traces. (b) Bulbous to tubular concentrations of iron oxides or iron carbonate locally form in association with the coarse calcite veins along faults. Locations: a) $27.17198 \mathrm{~N}$, 28.00866E; b) $27.15608 \mathrm{~N}, 28.02299 \mathrm{E}$. 


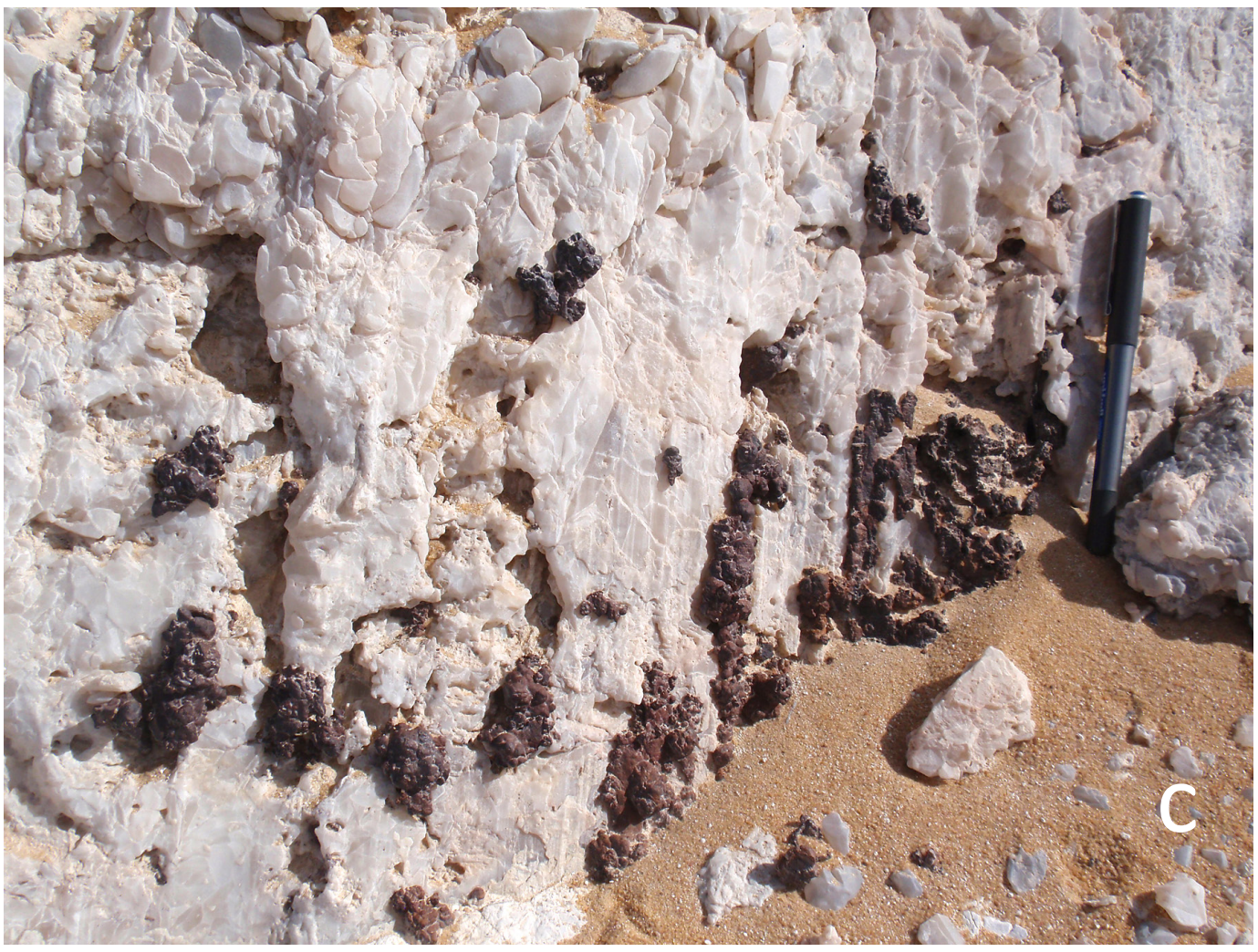

Figure DR10: (c) Botryoidal clusters of goethite (originally pyrite or marcasite) occurring along the grooves of a fault zone and postdating calcite mineralization. Pen is $13 \mathrm{~cm}$ long. Location: $27.18456 \mathrm{~N}, 28.02436 \mathrm{E}$. 


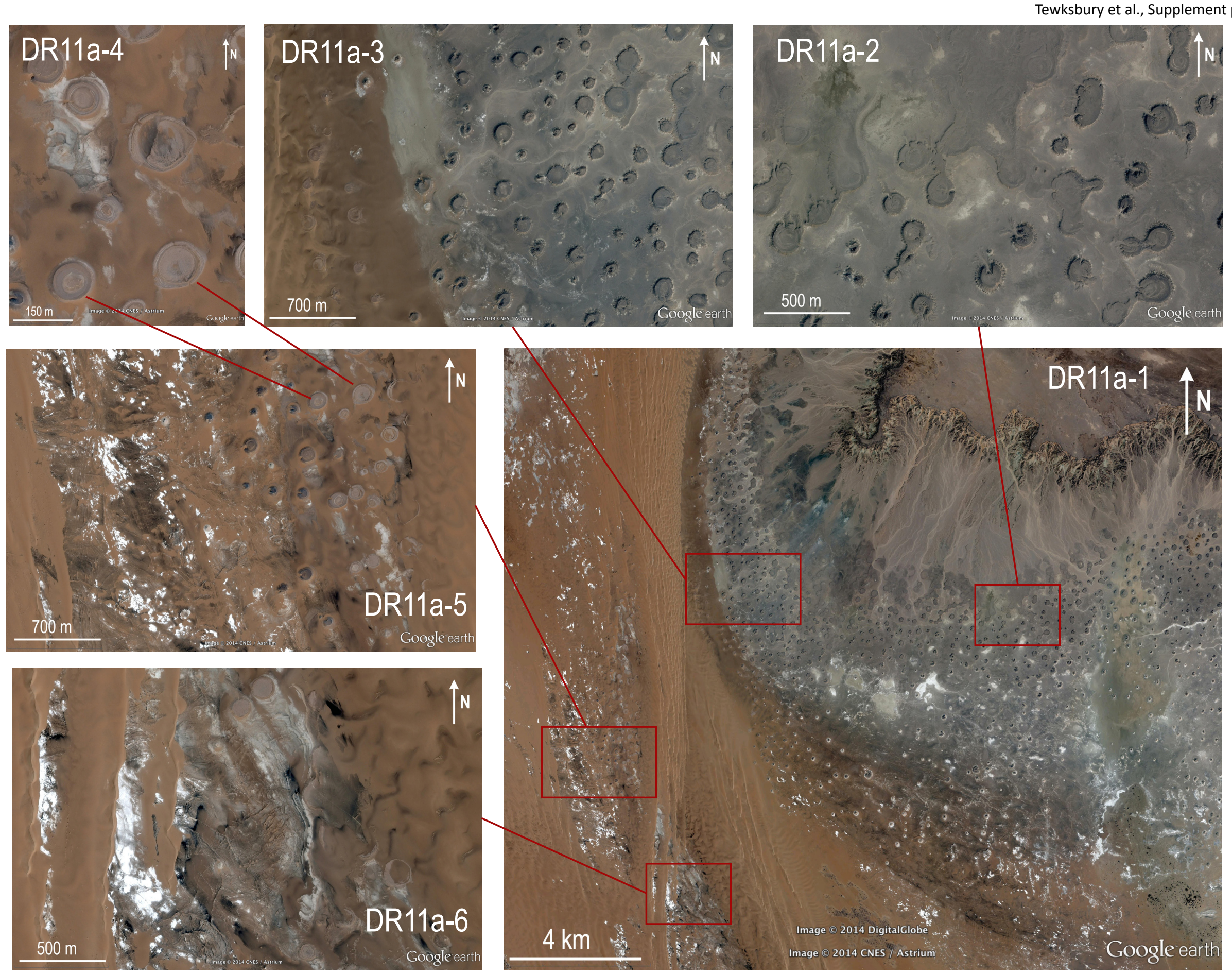

Figure DR11a: Caption appears on page 17. 
Figure DR11a (previous page): Google Earth images from the northeastern portion of the Farafra Valley show the distribution and characteristics of the small circular basins and their spatial relationship to the polygonal faults.

DR11a-1: The stratigraphically higher portions of the Khoman Formation occur in the central, north central and east central portions of this location map, with stratigraphically lower portions to the west, southwest, and south. The plateau in the northeast is capped by Eocene carbonates, and the top of the Khoman lies approximately at the base of the alluvial apron extending downslope from the escarpment at the edge of the plateau. The plateau lies about $200 \mathrm{~m}$ above the top of the Khoman Formation. Image center: $27.281167 \mathrm{~N}$, 28.478123E.

DR11a-2: This Google Earth image shows the transition from a continuous resistant layer in the Khoman Formation to isolated mesas eroded from the continuous layer. The image shows clearly that the small circular basins are part of a continuous, otherwise flat-lying layer and that inward dips of the basins protect the layer from erosion, forming the basin-capped mesas. Image center: 27.289421N, 28.525495E.

DR11a-3: Down section to the west, progressively deeper erosion and dissection reduces the size of the mesas until few remain. West and down section of the mesa terrain, low-relief circular basins, rather than basin-capped mesas, characterize the Khoman. Image center: $27.295527 \mathrm{~N}, 28.442470 \mathrm{E}$.

DR11a-4 through 6: DR11a-5 shows small circular basins (eastern part of the image) in close proximity to and slightly stratigraphically above polygonal faults (western part of the image and extending underneath the small circular basins to the east). DR11a-6 and enlarged image DR11a-4 show polygonal faults in the horizon stratigraphically beneath the small circular basins, as well as faults cutting up through some of the basins themselves. Image centers: DR11a-4 27.258995N, 28.406315E; DR11a-5 27.249787N, 28.399624E; DR11a-6 27.214930N, 28.425791E.

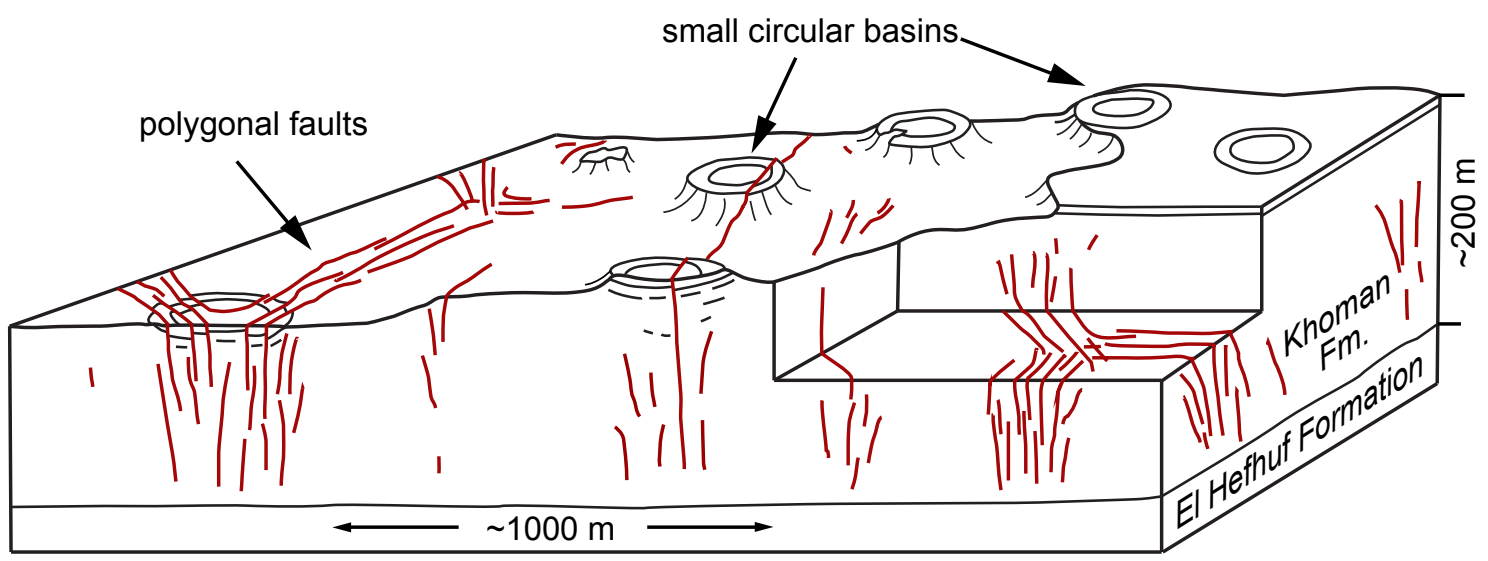

Figure DR11b: Full resolution of Fig. 3c. This schematic diagram is a composite portrayal of the spatial relationships among features in the Khoman Formation and is based on the relationships shown topographically, structurally, and stratigraphically in Figures DR8, DR9, and DR11a. 